\section{Prevalence and antibiotic susceptibility patterns of bacteria causing urinary tract infections in Youssef Hospital Center: first report from Akkar governorate, North Lebanon}

\section{Abstract}

Background. Urinary tract infection (UTI) is common infection feature worldwide. Infected patients are usually treated empirically treated without culture or antibiotics susceptibility testing, and which may lead to increase antibiotic resistance level. This study aims to determine the prevalence and antibiotic susceptibility patterns of common uropathogenic bacteria isolated at Youssef Hospital Center, Akkar governorate, North of Lebanon.

Methods. Spot midstream of urine samples from 9662 patients with UTI symptoms who came for medical investigation to Youssef Hospital Center located in Akkar governorate. Urine specimens were collected in sterile plastic bottles. Culture, identification and antibiotic susceptibility testing were performed using conventional tools according to the recommendations of the European Committee on Antimicrobial Susceptibility Testing.

Results. A total of 1009 bacterial uropathogens were isolated. Escherichia coli was most presented (72.5\%) of all isolates, followed by Klebsiella pneumoniae (8.2\%), Enterococcus spp. (5.5\%), Pseudomonas aeruginosa (4.5\%), Proteus spp. (3\%), Enterobacter spp. (2\%), Staphylococcus aureus (2\%), Streptococcus agalactiae (1.6\%), Staphylococcus saprophyticus (0.4\%), Acinetobacter baumannii (0.2\%) and Providencia rettgeri $(0.1 \%)$. Moreover, the mean antibiotic resistance rates of isolates was relatively high, but comparable to previously published data in Lebanon.
Marwan Osman ${ }^{1,2}$, Hassan Mallat ${ }^{1,2}$, Monzer Hamze', Elie Bou Raad ${ }^{2}$

\section{Laboratoire Microbiologie Santé et Environnement (LMSE), Ecole Doctorale des Sciences et de Technologie, Faculté de Santé Publique, Université Libanaise, Tripoli, Lebanon. \\ 2 Youssef Hospital Center, Akkar governorate, Lebanon}

Corresponding author:

Professor Dr. Monzer Hamze

”"umhamze@monzerhamze.com 
Conclusion. To the best of our knowledge, this is the first investigation reporting epidemiological data regarding the prevalence and antibiotic susceptibility patterns of bacterial uropathogens isolated from patients in the Akkar governorate. Our data indicated the urgent need of a strategic plan to tackle antibiotic resistance, particularly in deprived regions with poor healthcare centers.

Keywords: Uropathogens, Epidemiology, Antibiotic susceptibility, Risk factors, Akkar governorate, North Lebanon.

\section{Introduction}

Urinary tract infections (UTIS) are the most common infections in humans that can affect any part of the urinary system including kidneys, ureters, bladder, or urethra. It is estimated that approximately 150 million cases occur yearly globally each year [1]. Clinically, UTI is categorized as uncomplicated or complicated cases. Uncomplicated UTIs occur in healthy individuals and usually can be cured within 3 days of treatment. These infections are more common causing cystitis (lower UTI) and pyelonephritis (upper UTI) [2,3]. Numerous risk factors can increase the likelihood of developing a UTI, including female gender, sexual intercourse, poor personal hygiene, diabetes, obesity, vaginal infections and heavy use of antibiotics [4]. In contrast, complicated UTIs are found in an individual with factors that compromise the urinary tract or immune system, such as immunosuppression, renal failure, renal transplantation, pregnancy, problems of emptying the bladder completely, kidney stones and the presence of foreign bodies particularly indwelling catheters [5]. Additionally, this type of UTI requires longer periods of antibiotic treatment [6].

The leading pathogens of UTIs are caused mainly by Gram-negative bacteria including uropathogenic
Escherichia coli (E. coli), Klebsiella pneumoniae ( $K$. pneumoniae), Proteus mirabilis and Pseudomonas aeruginosa ( $P$. aeruginosa). Gram-positive bacteria like S. aureus, Staphylococcus saprophyticus (S. saprophyticus), Enterococcus faecalis (E. faecalis) and Streptococcus agalactiae (S. agalactiae), and yeasts like Candida spp. are also an important cause of UTIs [1].

Recently, The Center for Disease Control and Prevention $(C D C)$ declared that the human race is now in the post-antibiotic era [7]. The World Health Organization (WHO) also warned that the antibiotic resistance crisis is becoming serious all around the world [7]. In the past decade in Lebanon, several recent studies documented the occurrence of high rates of antibiotic resistant bacteria [8-21]. However, no data was reported from the Akkar governorate located in North of Lebanon. Akkar covers 788 km² of territory and is one of the most deprived regions in Lebanon. It shows all the typical features of a poor and relatively isolated rural community, with bad infrastructure and low quality of education and health services.

For this reason, we conducted this investigation in order to determine for the first time the prevalence of bacterial pathogens causing UTIs and their antibiotic susceptibility profiles of isolates from pa- 
tients in Youssef hospital center in the Akkar governorate, North of Lebanon.

\section{Material and Methods}

This study was conducted in the clinical microbiology laboratory of Youssef hospital center in the Akkar governorate during the period from September 2015 to January 2017. This hospital created in 1995, contains 120 beds available to deliver highquality patient care in one center. Spot midstream of urine samples were collected from 9662 patients presenting with UTI symptoms. The sterile urine specimens transported immediately to the microbiology department. The count of white bloodcells (WBC) was carried out on centrifuged urine specimens using routine microscopy. Culture of uncentrifuged specimens was performed using a calibrated loop (10 $\mu \mathrm{l}$ ) on UriSelect ${ }^{\mathrm{TM}} 4$ agar (Bio-Rad ${ }^{\circledR}$, France) after an incubation for 18 to 24 hours at $35^{\circ} \mathrm{C}$. The bacterial identification was performed according to the manufacturer's recommended procedures and through the use of API-20E and API-20NE (bioMérieux $^{\circledR}$ - France), Pastorex ${ }^{\mathrm{TM}}$ Staph Plus kit (Bio-Rad ${ }^{\circledR}$, France), and Pastorex ${ }^{\top M}$ Strep kits (Bio-Rad ${ }^{\circledR}$, France).

The antibiotic susceptibility testing was performed by the disk diffusion method on Mueller Hinton agar for Enterobacteriaceae and non-Enterobacteriaceae Gram negative rods, Staphylococcus spp., Enterococcus spp. (Bio-Rad ${ }^{\circledR}$, France), and on Mueller Hinton agar supplemented with $5 \%$ blood and $20 \mathrm{mg} / \mathrm{l}$ $\beta$-NAD (MHF) for $S$. agalactiae according to the recommendations of the European Committee on Antimicrobial Susceptibility Testing (EUCAST).

In addition, statistical analyses were performed with GraphPad Prism 6.0 (GraphPad Software Inc., SanDiego, (A) using the Fisher's exact test to explorethe association between gender and infection, and betweenthe sex ratio (male/female) and the age of infected patients ( $<70$ years and $\geq 70$ years). The general significance level was set at a P-value below 0.05 .

\section{Results}

A total of 9662 consecutive urine samples were included in our study. Of these, 8653 (89.6\%) were negative for the growth of bacteria or showed insignificant growth, and 1009 (10.4\%) were positive for significant bacterial growth. Among positive samples, 244 belonged to males and 765 belonged to females, ranging in age from 1 month to 97 years, with a mean age of 47.5 years. All the patients came from the Akkar governorate. Moreover, the positive patients had more than 200 white blood cells $/ \mathrm{mm}^{3}$ in their urine specimens as determined by routine microscopy. E. coli caused the highest infection rate $(72.5 \%)$, followed by $K$. pneumoniae (8.2\%), Enterococcus spp. (5.5\%), P. aeruginosa $(4.5 \%)$, Proteus spp. (3\%), Enterobacter spp. (2\%), S. aureus $(2 \%)$, S. agalactiae $(1.6 \%)$, S. saprophyticus $(0.4 \%)$, Acinetobacter baumannii (A. baumannii) $(0.2 \%)$ and Providencia rettgeri (P. rettgeri) (0.1\%).

Tables 1 and $\mathbf{2}$ express distribution of the major bacterial isolates based age and sex of patients, respectively.The mean sex ratio (male/female) of infection was 0.32. The sex ratio (male/female) of urine infections showed the lower rates among the children and younger populations and the higher rates among older populations, particularly in patients aged more than 70 years (Figure 1). In addition, according to EUCAST guidelines, the mean percentages of susceptibility of Gram-negative and Gram-positive isolates are showed in Table 3, 4 and $\mathbf{5}$, respectively.

\section{Discussion}

To our best knowledge, the present study represents the first investigation from a hospital in the Akkar governorate, North of Lebanon. In addition, no data is available in the literature regarding to the distribution of bacterial uropathogens and their antibiotic resistance patterns in this region. Hence, this investigation provides important labo- 
Table 1. Distribution of the isolatedbacterial strains according to the age of patients

\begin{tabular}{|c|c|c|c|c|c|c|c|c|c|c|c|c|}
\hline Age class & 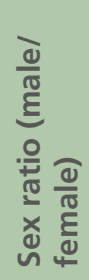 & 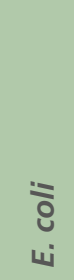 & 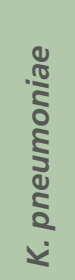 & $\begin{array}{l}\frac{0}{0} \\
\text { n } \\
\text { y } \\
0 \\
0 \\
0\end{array}$ & 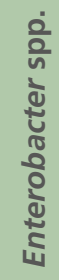 & 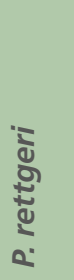 & 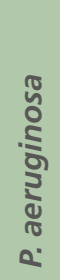 & 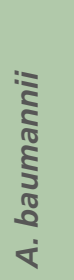 & 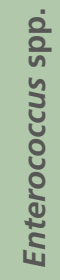 & 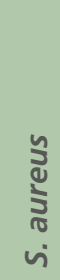 & 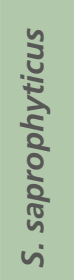 & 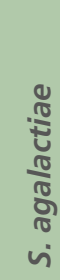 \\
\hline [0-10] & 0.21 & 139 & 7 & 6 & 3 & 0 & 6 & 1 & 13 & 1 & 1 & 0 \\
\hline [10-20] & 0.12 & 21 & 1 & 2 & 1 & 0 & 0 & 0 & 1 & 2 & 0 & 0 \\
\hline [20-30] & 0.11 & 73 & 15 & 4 & 3 & 0 & 9 & 0 & 6 & 8 & 0 & 3 \\
\hline [30-40] & 0.09 & 59 & 7 & 4 & 0 & 0 & 4 & 0 & 7 & 1 & 1 & 2 \\
\hline [40-50] & 0.40 & 51 & 3 & 1 & 2 & 0 & 10 & 0 & 0 & 1 & 0 & 2 \\
\hline [50-60] & 0.35 & 74 & 8 & 1 & 2 & 0 & 4 & 0 & 6 & 2 & 0 & 3 \\
\hline$[60-70]$ & 0.35 & 99 & 14 & 2 & 2 & 0 & 2 & 0 & 6 & 1 & 0 & 2 \\
\hline [70-80] & 0.55 & 120 & 15 & 4 & 7 & 0 & 4 & 0 & 10 & 1 & 1 & 2 \\
\hline [80-90] & 0.69 & 79 & 11 & 4 & 0 & 1 & 3 & 1 & 5 & 3 & 1 & 2 \\
\hline$[90-100]$ & 0.65 & 17 & 2 & 2 & 0 & 0 & 3 & 0 & 2 & 0 & 0 & 0 \\
\hline Total & 0.32 & 732 & 83 & 30 & 20 & 1 & 45 & 2 & 56 & 20 & 4 & 16 \\
\hline
\end{tabular}

Table 2. Distribution of the isolated bacterial strains according to the sex of patients and inpatient/ outpatient status

\begin{tabular}{|l|c|c|c|c|c|c|}
\hline \multicolumn{1}{|c|}{ Bacteria } & Male & Female & $\begin{array}{c}\text { Sex ratio (male/ } \\
\text { female) }\end{array}$ & $\begin{array}{c}\text { Inpatient } \\
\text { status }\end{array}$ & $\begin{array}{c}\text { Outpatient } \\
\text { status }\end{array}$ & Total (\%) \\
\hline E. coli & 154 & 578 & 0.27 & 475 & 257 & $732(72.5 \%)$ \\
\hline K. pneumoniae & 17 & 66 & 0.26 & 62 & 21 & $83(8.2 \%)$ \\
\hline Proteus spp. & 10 & 20 & 0.5 & 13 & 17 & $30(3 \%)$ \\
\hline Enterobacter spp. & 5 & 15 & 0.33 & 15 & 5 & $20(2 \%)$ \\
\hline P. aeruginosa & 25 & 20 & 1.25 & 33 & 12 & $45(4.5 \%)$ \\
\hline Enterococcus spp. & 21 & 35 & 0.6 & 30 & 26 & $56(5.5 \%)$ \\
\hline S. aureus & 5 & 15 & 0.33 & 9 & 11 & $20(2 \%)$ \\
\hline S. agalactiae & 4 & 12 & 0.33 & 9 & 7 & $16(1.6 \%)$ \\
\hline Others & 3 & 4 & 0.75 & 4 & 3 & $7(0.7 \%)$ \\
\hline Total & $\mathbf{2 4 4}$ & $\mathbf{7 6 5}$ & $\mathbf{0 . 3 2}$ & $\mathbf{6 5 0}$ & $\mathbf{3 5 9}$ & $\mathbf{1 0 0 9}$ \\
\hline
\end{tabular}




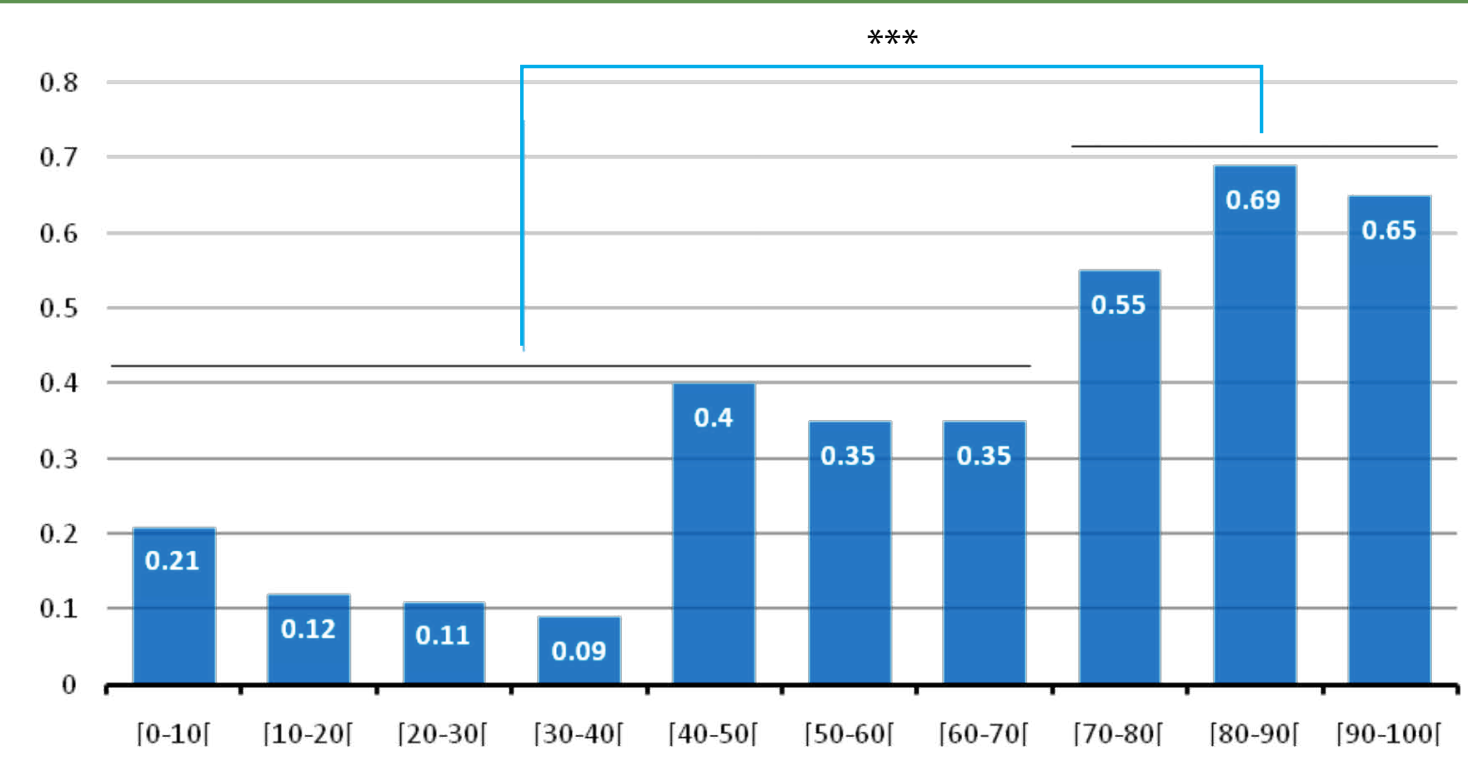

Figure 1. The variation of the sex ratio (male/female) according to the age of infected patients.

ratory data that could support national surveillance of antibiotic resistance and will improve treatment recommendations in this geographical region of our country. Overall, a total of 1009 isolates were collected from Akkari patients. The majority of urine infection cases were found in female (765/1009). A significant gender difference in the prevalence of the infection was found (OR: $3.5 \mathrm{Cl}$ : 3.0-4.1, $\mathrm{P}<0.0001)$ as reported in other study [1].Women, particularly sexually active and aged between 16 and 64 years have significantly more risk to experience UTIs than men because they have a shorter urethra [22]. However, UTIs often occur in both genders and across all age groups, including elderly population [23]. In the same context, the sex ratio (male/female) has significantly increased with age, particularly in patients older than 70 years (OR: 2.6 $\mathrm{Cl}$ : 1.9-3.5, $\mathrm{P}<0.0001)$. Older adults are associated with high burden of UTI and need improvement in diagnosis and treatment of their infections. According to our laboratory records, E. coli was the most common pathogen causing UTIs, followed by other well-known uropathogens; K. pneumoniae, Proteus spp, Enterobacter spp. and $P$. aeruginosa (Table 3) and these results are comparable to other studies from various countries $[22,24]$. No significant difference was found concerning the distribution of uropathogens according to age of patients. All types of bacterial pathogens were found in both females and males. However, out of all $P$. aeruginosa isolates, 13 (28.9\%) were from hospitalized patients. This organism is becoming an important cause of UTI associated with hospital-acquired UTIs [1].

Furthermore, this investigation showed a relatively high antibiotic resistance rates among the majority of uropathogens isolated in our hospital (Tables 3-5). E. coli isolates showed high level of resistance to commonly used empirical antibiotics such asbetalactams, quinolones and trimethoprim/sulfamethoxazole. In the present study, $35.7 \%$ of $E$. coli isolates were ESBL-producers. Our findings showed similar percentages of resistance to antibiotics described in previous studies conducted in Lebanon. Numerous recent investigations found a high prevalence of ESBL-producing E. coli $[8,15,25]$. Moreover, we found that resistance to ertapenem, imipenem and 
Table 3. Percentage of antibiotic susceptibility of major Gram-negative bacilli isolates.

\begin{tabular}{|c|c|c|c|c|c|}
\hline & $\begin{array}{c}\text { E.coli } \\
N=732 \\
(\%)\end{array}$ & $\begin{array}{c}\text { K. pneumoniae } \\
\mathrm{N}=83 \\
(\%)\end{array}$ & $\begin{array}{l}\text { Proteus spp. } \\
\qquad \begin{array}{c}\mathrm{N}=30 \\
(\%)\end{array}\end{array}$ & $\begin{array}{l}\text { Enterobacter spp. } \\
\qquad \begin{array}{c}\mathrm{N}=20 \\
(\%)\end{array}\end{array}$ & $\begin{array}{c}\text { P. aeruginosa } \\
\mathrm{N}=45 \\
(\%)\end{array}$ \\
\hline AMP & 26.2 & 0 & 30 & 0 & - \\
\hline AMC & 79.6 & 89.2 & 83.3 & 0 & - \\
\hline TIC & 29.2 & 0 & 40 & 85 & 64.4 \\
\hline TCC & 82.0 & 86.7 & 93.3 & 90 & 64.4 \\
\hline PIP & 29.2 & 0 & 40 & 85 & 64.4 \\
\hline PPT & 90.7 & 90.4 & 93.3 & 95 & 64.4 \\
\hline CFX & 50.5 & 68.7 & 70 & 0 & - \\
\hline CXM & 53.3 & 68.7 & 70 & 85 & - \\
\hline FOX & 84.2 & 95.2 & 83.3 & 0 & - \\
\hline CFM & 57.9 & 71.1 & 80 & 90 & - \\
\hline СТХ & 60.1 & 71.1 & 83.3 & 90 & - \\
\hline CAZ & 63.3 & 73.5 & 83.3 & 90 & 71.1 \\
\hline FEP & 68.6 & 75.9 & 90 & 95 & 71.1 \\
\hline ATM & 62.7 & 72.3 & 90 & 90 & - \\
\hline ERT & 98.9 & 98.8 & 100 & 95 & - \\
\hline IMP & 99.6 & 100 & 100 & 100 & 60 \\
\hline MEM & 99.6 & 100 & 100 & 100 & 60 \\
\hline GMN & 80.1 & 77.1 & 66.7 & 100 & 93.3 \\
\hline TMN & 73.4 & 74.7 & 63.3 & 95 & 93.3 \\
\hline NET & 99.6 & 98.8 & 76.7 & 100 & 95.6 \\
\hline AKN & 99.3 & 100 & 90 & 100 & 93.3 \\
\hline NA & 45.5 & 71.1 & 46.7 & 90 & - \\
\hline NXM & 60.5 & 74.7 & 53.3 & 95 & - \\
\hline CIP & 61.7 & 74.7 & 56.7 & 95 & 53.3 \\
\hline LVX & 61.7 & 79.5 & 56.7 & 95 & 53.3 \\
\hline TGC & 99.9 & - & - & - & - \\
\hline CS & 100 & 100 & 0 & 100 & 100 \\
\hline FSF & 98.9 & 92.8 & 66.7 & 75 & 88.9 \\
\hline FUR & 99.3 & 89.2 & 0 & 85 & - \\
\hline SXT & 55.7 & 55.4 & 43.3 & 80 & - \\
\hline
\end{tabular}

AMP, ampicillin $(10 \mu \mathrm{g}) ; \mathrm{AMC}$, amoxicillin/clavulanate $(20 / 10 \mu \mathrm{g}) ; \mathrm{TIC}$, ticarcillin $(75 \mu \mathrm{g})$; TCC, ticarcillin/clavulanate $(75 / 10 \mu \mathrm{g})$; PIP, piperacillin $(30 \mu \mathrm{g})$; PPT, piperacillin/tazobactam $(30 / 4 \mu \mathrm{g})$; ATM, aztreonam $(30 \mu \mathrm{g})$; IMP, imipenem (10 $\mu \mathrm{g})$; MEM, meropenem $(10 \mu \mathrm{g})$; ERT, ertapenem $(10 \mu \mathrm{g})$; CFX, cefalexin $(30 \mu \mathrm{g})$; CXM, cefuroxime $(30 \mu \mathrm{g})$; FOX, cefoxitin (30 $\mu \mathrm{g})$; CFM, cefixim (5 $\mu \mathrm{g})$; CTX, cefotaxime $(5 \mu \mathrm{g})$; FEP, cefepime $(30 \mu \mathrm{g}) ; \mathrm{CAZ}$, ceftazidime $(30 \mu \mathrm{g}) ; \mathrm{GMN}$, gentamicin $(10 \mu \mathrm{g})$; TMN, tobramycin $(10 \mu \mathrm{g})$; AKN, amikacin $(30 \mu \mathrm{g})$; NET, netilmicin $(10 \mu \mathrm{g})$; NA, nalidixic acid $(30 \mu \mathrm{g})$; NXM, norfloxacin $(10 \mu \mathrm{g})$; CIP, ciprofloxacin $(5 \mu \mathrm{g})$; LVX, levofloxacin $(5 \mu \mathrm{g})$; TGC, tigecycline $(15 \mu \mathrm{g})$; CS, colistin $(50 \mu \mathrm{g})$; FSF, fosfomycin $(200 \mu \mathrm{g})$; FUR, nitrofurantoin $(100 \mu \mathrm{g})$; SXT, trimethoprim/sulfamethoxazole $(1,25 / 23,75 \mu \mathrm{g})$. 
Table 4. Percentage of antibiotic susceptibility of ESBL-producing isolates.

\begin{tabular}{|c|c|c|c|}
\hline & $\begin{array}{c}\text { E. coli } \\
N=261 \\
(\%)\end{array}$ & $\begin{array}{c}\text { K. pneumoniae } \\
\mathrm{N}=23 \\
(\%)\end{array}$ & $\begin{array}{l}\text { Proteus spp. } \\
\qquad \begin{array}{c}\mathrm{N}=4 \\
(\%)\end{array}\end{array}$ \\
\hline AMP & 0 & 0 & 0 \\
\hline AMC & 82.4 & 95.7 & 100 \\
\hline TIC & 0 & 0 & 0 \\
\hline TCC & 75.1 & 82.6 & 100 \\
\hline PIP & 0 & 0 & 0 \\
\hline PPT & 88.9 & 95.7 & 100 \\
\hline CFX & 0 & 0 & 0 \\
\hline CXM & 0 & 0 & 0 \\
\hline FOX & 85.4 & 95.7 & 100 \\
\hline CFM & 2.7 & 4.3 & 25 \\
\hline СТХ & 1.9 & 0 & 0 \\
\hline CAZ & 13 & 13 & 25 \\
\hline FEP & 16.9 & 17.4 & 25 \\
\hline ATM & 8 & 8.7 & 25 \\
\hline ERT & 100 & 100 & 100 \\
\hline IMP & 100 & 100 & 100 \\
\hline MEM & 100 & 100 & 100 \\
\hline GMN & 58.6 & 34.8 & 25 \\
\hline TMN & 43.3 & 21.7 & 25 \\
\hline NET & 99.6 & 100 & 25 \\
\hline AKN & 99.6 & 100 & 25 \\
\hline NA & 20.3 & 30.4 & 25 \\
\hline NXM & 34.5 & 34.7 & 25 \\
\hline CIP & 35.2 & 34.7 & 25 \\
\hline LVX & 35.2 & 47.8 & 25 \\
\hline TGC & 100 & - & - \\
\hline CS & 100 & 100 & 0 \\
\hline FSF & 98.1 & 87 & 50 \\
\hline FUR & 100 & 91.3 & 0 \\
\hline SXT & 36 & 8.7 & 0 \\
\hline
\end{tabular}

meropenem was about $1.1 \%, 0.4 \%$ and $0.4 \%$, respectively. Several recent studies reported the emergence carbapenem-resistance strains in North of Lebanon, mainly by OXA-48 production [25-30]. Gentamicin and ciprofloxacin resistance were about $19.9 \%$ and $38.3 \%$, respectively, which are in the range of previous community based studies in Lebanon $[8,15,18,25]$. Regarding to the other isolated
Enterobacteriaceae, the resistance rate was lower than that observed in E. coli isolated isolates, except with Proteus spp. which had the highest resistance rate between isolates of Enterobacteriaceae to fluoroquinolones, with $46.7 \%$ to norfloxacin, $43.3 \%$ to ciprofloxacin and $43.3 \%$ to levofloxacin. Furthermore, this study showed a trend of increasing resistance in $P$. aeruginosa isolates to all commonly used antibiotic agents. $P$. aeruginosa resistance to carbapenem and fluoroquinolones was $40 \%$ and $46.7 \%$, higher than the previous rates of $(8.7 \%$ to $28.5 \%$ and 8.7 to $20 \%$, respectively) which was reported in other studies $[8,13]$. The rise in carbapenem resistance could be the result of increasing use of carbapenem and which is associated with spread of ESBL-producing strains in the last few years in Lebanon [8]. In the same context, the increase of fluoroquinolone resistance could be explained by the misuse and overuse of this class of antibiotics in the Middle East region.

Among Gram-positive cocci isolates, Enterococcus spp. was the predominant, followed by S. aureus, S. agalactiae, and S. saprophyticus (Table 5). The susceptibility of Enterococcus spp. to ampicillin and imipenem was equal to $73.2 \%$. High level of resistance was recorded to trimethoprim/sulfamethoxazole, tetracycline, ampicillin, imipenem, erythromycin and fluoroquinolones (Table 5). No vancomycin-resistant enterococci was observed in our study. During the last decade, limited studies were done dealing with the identification of Enterococcus spp. circulating in Lebanon and their antibiotic resistance patterns. A recent study in Lebanon has showed that among 53 Enterococcus spp. isolates, E. faecalis was predominant $(72.5 \%)$, followed by Enterococcus faecium (22.9\%), Enterococcus avium (3.3\%) and Enterococcus gallinarum (1.3\%) [31].

With regard to $S$. aureus, the clinical significance of a positive urine culture for this pathogen is still unclear. Recent studies have reported that S. aureus can cause approximately 0.5 to $6 \%$ of UTIs [32]. The prevalence of methicillin-resistant S. aureus 
Table 5. Percentage of antibiotic susceptibility of major Gram-positive cocci isolates.

\begin{tabular}{|c|c|c|c|}
\hline & $\begin{array}{l}\text { S. aureus } \\
\mathrm{N}=20 \\
(\%)\end{array}$ & $\begin{array}{l}\text { Enterococcus spp. } \\
\qquad \begin{array}{l}\mathrm{N}=56 \\
(\%)\end{array}\end{array}$ & $\begin{array}{c}\text { S. agalactiae } \\
\begin{array}{c}\mathrm{N}=16 \\
(\%)\end{array}\end{array}$ \\
\hline PG & 10 & - & 100 \\
\hline AMP & - & 73.2 & - \\
\hline FOX & 70 & - & - \\
\hline IMP & - & 73.2 & - \\
\hline VAN & 100 & 100 & 100 \\
\hline TEI & 100 & 100 & 100 \\
\hline FSF & 90 & 89.3 & - \\
\hline$E$ & 60 & 35.7 & 68.8 \\
\hline$C D$ & 95 & - & 75 \\
\hline PTN & 100 & - & 100 \\
\hline TET & 75 & 15.4 & 25 \\
\hline TGC & 100 & 100 & 100 \\
\hline GMN & 85 & 73.2 & 87.5 \\
\hline LZD & 100 & 100 & 100 \\
\hline FUS & 100 & - & - \\
\hline NXM & 85 & 64.3 & 87.5 \\
\hline LVX & 85 & 64.3 & 87.5 \\
\hline RIF & 100 & 60.7 & 93.8 \\
\hline SXT & 95 & 10.7 & 43.8 \\
\hline FUR & 100 & 96.4 & 100 \\
\hline
\end{tabular}

PG, penicillin G (1 unit); AMP, ampicillin $(2 \mu \mathrm{g})$; FOX, cefoxitin (30 $\mu \mathrm{g})$; IMP, imipenem (10 $\mu \mathrm{g})$; GMN, gentamicin $(10 \mu \mathrm{g}$ for S. aureus; $30 \mu \mathrm{g}$ for Enterococcus spp. and $500 \mu \mathrm{g}$ for $\mathrm{S}$. agalactiae); TET, tetracycline $(30 \mu \mathrm{g})$; TGC, tigecycline $(15 \mu \mathrm{g})$; $\mathrm{E}$, erythromycin (15 $\mu \mathrm{g}) ; \mathrm{CD}$, clindamycin (2 $\mu \mathrm{g}) ;$ PTN, pristinamycin $(15 \mu \mathrm{g})$; LZD, linezolid $(10 \mu \mathrm{g})$; TEl, teicoplanin $(30 \mu \mathrm{g})$; VAN, vancomycin $(5 \mu \mathrm{g})$; NXM, norfloxacin $(10 \mu \mathrm{g})$; LVX, levofloxacin $(5 \mu \mathrm{g})$; FUS, fusidic acid $(10 \mu \mathrm{g})$; FSF, fosfomycin $(200 \mu \mathrm{g})$; RIF, Rifampicin $(5 \mu \mathrm{g}) ;$ SXT, trimethoprim/sulfamethoxazole $(1,25 / 23,75 \mu \mathrm{g})$; FUR, nitrofurantoin $(100 \mu \mathrm{g})$.

(MRSA), based on cefoxitin resistance was higher than that reported in nasal secretions of healthy school children in Tripoli, north of Lebanon [33]. In addition, Chamoun et al. [8] reported an increase in the prevalence of MRSA between 2011 and 2013 in Lebanese hospitals. Therefore, there is urgent need to control and prevent transmission of MRSA infections in hospitalized patients. Contamination through MRSA frequently occurs by direct skin-toskin contact or shared items and is often associated with poor hygiene practices in hospitals [34]. However, all S. aureus isolates in our study were susceptible to vancomycin, teicoplanin and linezolid. Concerning S. agalactiae isolates, 100\% susceptibility rate was observed to penicillin, vancomycin, teicoplanin, pristinamycin, tigecycline and nitrofurantoin, and high susceptibility rates were demonstrated to fluoroquinolones and rifampicin, respectively (Table 5). High levels of resistance were also recorded to tetracycline, trimethoprim/sulfamethoxazole, and less to erythromycin and clindamycin (Table 5). These findings are higher than the respective rates reported previously in our country [31].

Overall, our data indicate that antibiotic resistance rates of bacterial uropathogens are relatively high in the Akkari patients, and are much comparable to previous community based studies conducted in Lebanon. The increase in antibiotic resistance rates is now becoming a major problem in the Akkar Governorate as well as in the whole country. High resistant rates among uropathogenic bacteria will certainly contribute to antibiotic selective pressures, maintain and spread of resistant strains in our community. Additionally, antibiotic selective pressure is usually linked to high spread of counterfeit medicines, misuse and overuse of antibiotics.

In conclusion, a national strategic plan is urgently needed to combat antibiotic resistance in all regions of Lebanon. A good antibiotic stewardship plan should aim to ensure the appropriate use of antibiotics and reduce the risk of infection with drugresistant organisms.

\section{Acknowledgements}

We would like to thank Nancy Mostafa and YollaAyoub for their excellent technical assistance. 


\section{Competing Interests}

The authors declare that they have no competing interests.

\section{References}

1. Flores-Mireles AL, Walker JN, Caparon M, Hultgren SJ. Urinary tract infections: epidemiology, mechanisms of infection and treatment options. Nat Rev Microbiol 2015;13(5):269-84.

2. Hooton TM. Clinical practice. Uncomplicated urinary tract infection. N Engl J Med 2012; 366(11):1028-37.

3. Nielubowicz GR, Mobley HL. Host-pathogen interactions in urinary tract infection. Nat Rev Urol 2010;7(8):430-41.

4. Hannan TJ, Totsika M, Mansfield KJ, Moore KH, Schembri MA, Hultgren SJ. Host-pathogen checkpoints and population bottlenecks in persistent and intracellular uropathogenic Escherichia coli bladder infection. FEMS Microbiol Rev 2012;36(3):616-48.

5. Lichtenberger $P$, Hooton TM. Complicated urinary tract infections. Curr Infect Dis Rep 2008;10(6):499-504.

6. Levison ME, Kaye D. Treatment of complicated urinary tract infections with an emphasis on drug-resistant gram-negative uropathogens. Curr Infect Dis Rep 2013;15(2):109-15.

7. Ventola CL. The antibiotic resistance crisis: part 1: causes and threats. P T 2015;40(4):277-83.

8. Chamoun K, Farah M, Araj G, Daoud Z, Moghnieh R, Salameh $P$, et al. Surveillance of antimicrobial resistance in Lebanese hospitals: retrospective nationwide compiled data. Int J Infect Dis 2016;46:64-70.

9. Charrouf FO, Hamze M, Mallat H, Achkar M, Dabboussia F. Characterization of resistance genes in 68 ESBL-producing Klebsiella pneumonia in Lebanon. Med Mal Infect 2014;44(1112):535-8.

10. Dabboussi F, Alam S, Mallat H, Hlais S, Hamze M. [Preliminary study on the prevalence of Campylobacter in childhood diarrhoea in north Lebanon]. East Mediterr Health J 2012;18(12):1225-8.

11. Dabboussi F, Allouche S, Mallat $H$, Hamze M. Prevalence of first-step mutants among levofloxacin-susceptible isolates of Streptococcus pneumoniae in north Lebanon. J Chemother 2013;25(6):328-31.

12. Dabboussi F, El Omari K, Mouzawak M, Al Bayssari C, Hamze M. Recherche de Salmonella, Listeria et de bactéries résistantes aux céphalosporines de troisième génération dans du fromage Akkawi au nord du Liban. Lebanese Science Journal 2013;14(1):3-14.

13. Hamze $M$, Mallat $H$, Dabbousi F, Achkar M. Antibiotic susceptibility and serotyping of clinical strains of Pseudomonas aeruginosa isolated in northern Lebanon. IAJAA 2012;2(4:2):1-6.

14. Hamze M, Osman M, Achkar M, Mallat $H$, Dabboussi $F$. Alarming increase in prevalence of Neisseria gonorrhoeae infections associated with a high level of antibiotic resistance in Tripoli, Lebanon. IAJAA 2016; 48(5):576-7.
15. Hamze M, Osman M, Mallat H, Achkar M. Antibiotic Susceptibility of Salmonella spp., Shigella spp. and enteropathogenic Escherichia coli strains isolated from diarrheic children in Tripoli, North Lebanon. IAJAA 2016;6(2:2).

16. Osman M, Al Nasbeh A, Rafei R, Mallat H, Achkar M, Dabbousi $\mathrm{F}$, et al. Characterization of resistance genes to macrolides, lincosamides and streptogramins (MLS) among clinical isolates of Staphylococcus aureus in North Lebanon. IAJAA 2015;5(4:3):1-8.

17. Salma R, Dabboussi F, Kassaa I, Khudary R, Hamze M. gyrA and parC mutations in quinolone-resistant clinical isolates of Pseudomonas aeruginosa from Nini Hospital in North Lebanon. J Infect Chemother 2013;19(1):77-81.

18. Tabbouche $S$, Al Khudary R, Beyrouthy R, Dabbousi F, Achkar $\mathrm{M}$, Mallat $\mathrm{H}$, et al. Detection of genes TEM, OXA, SHV and CTX-M in 73 clinical isolates of Escherichia coli producers of extended spectrum Beta-lactamases and determination of their susceptibility to antibiotics. IAJAA 2011;1:1-6.

19. Yehya $M$, Hamze $M$, Mallat $H$, Dabbousi F. Prevalence and antibiotic susceptibility of Bacteroides fragilis group isolated from stool samples in North Lebanon. Braz J Microbiol 2013;44(3):807-12.

20. El Ashkar S, Osman M, Rafei R, Mallat H, Achkar M, Dabboussi $\mathrm{F}$, et al. Molecular detection of genes responsible for macrolide resistance among Streptococcus pneumoniae isolated in North Lebanon. J Infect Public Health. 2017, Pii: S18760341(17)30026-6.

21. Diab M, Hamze M, Madec JY, Haenni M. High Prevalence of Non-ST131 CTX-M-15-Producing Escherichia coli in Healthy Cattle in Lebanon. Microb Drug Resist. 2017;23(2):261-6.

22. Tandogdu Z, Wagenlehner FM. Global epidemiology of urinary tract infections. Curr Opin Infect Dis. 2016;29(1):73-9.

23. Magliano E, Grazioli V, Deflorio L, Leuci Al, Mattina R, Romano $P$, et al. Gender and age-dependent etiology of communityacquired urinary tract infections. Scientific World Journal 2012;2012:349597.

24. Karlowsky JA, Jones ME, Thornsberry C, Critchley I, Kelly LJ, Sahm DF. Prevalence of antimicrobial resistance among urinary tract pathogens isolated from female outpatients across the US in 1999. Int J Antimicrob Agents 2001;18(2):121-7.

25. Amrieh S, Hamze M, Mallat H, Achkar M, Dabboussi F. Detection of Escherichia coli 0157:H7 and 0104:H4 in patients with diarrhea in Northern Lebanon and characterization of fecal E. coli producing ESBL and carbapenemase genes. IAJAA 2014;4(3:4).

26. Al Bayssari C, Olaitan AO, Dabboussi F, Hamze M, Rolain JM. Emergence of OXA-48-producing Escherichia coli clone ST38 in fowl. Antimicrob Agents Chemother. 2015;59(1):745-6.

27. Al-Bayssari $C$, Olaitan $A O$, Leangapichart $T$, Okdah L, Dabboussi $\mathrm{F}$, Hamze $\mathrm{M}$, et al. Whole-Genome Sequence of a blaOXA48-harboring Raoultella ornithinolytica Clinical Isolate from Lebanon. Antimicrob Agents Chemother 2016;60(4):2548-50.

28. Beyrouthy R, Robin F, Cougnoux A, Dalmasso G, DarfeuilleMichaud A, Mallat $\mathrm{H}$, et al. Chromosome-mediated OXA-48 carbapenemase in highly virulent Escherichia coli. J Antimicrob Chemother 2013;68(7):1558-61. 
29. Beyrouthy R, Robin F, Dabboussi F, Mallat H, Hamze M, Bonnet R. Carbapenemase and virulence factors of Enterobacteriaceae in North Lebanon between 2008 and 2012: evolution via endemic spread of OXA-48. J Antimicrob Chemother 2014;69(10):2699-705.

30. Christophy R, Osman M, Mallat H, Achkar M, Ziedeh A Moukaddem $W$, et al. Prevalence, antibiotic susceptibility and characterization of antibiotic resistant genes among carbapenem-resistant Gram-negative bacilli and yeast in intestinal flora of cancer patients in North Lebanon. J Infect Public Health 2017, pii: S1876-0341(17)30044-8.

31. Araj GF, Avedissian AZ, Ayyash NS, Bey HA, El Asmar RG, Hammoud RZ, et al. A reflection on bacterial resistance to antimicrobial agents at a major tertiary care center in Lebanon over a decade. J Med Liban 2012;60(3):125-35.

32. Baraboutis IG, Tsagalou EP, Lepinski JL, Papakonstantinou I, Papastamopoulos V, Skoutelis AT, et al. Primary Staphylococcus aureus urinary tract infection: the role of undetected hematogenous seeding of the urinary tract. Eur J Clin Microbiol Infect Dis 2010;29(9):1095-101.

33. Beyrouthy R, Hamze M, Hleis S, Mallat H, Dabboussi F. PantonValentine leukocidin producing Staphylococcus aureus nasal carriage, in North-Lebanon. Med Mal Infect 2013;43(9):38690 .

34. Cooper BS, Stone SP, Kibbler CC, Cookson BD, Roberts JA, Medley GF, et al. Isolation measures in the hospital management of methicillin resistant Staphylococcus aureus (MRSA): systematic review of the literature. BMJ 2004;329(7465):533.

\section{Comment on this article:}

\section{f) $[$ in $\mathbf{S}$}

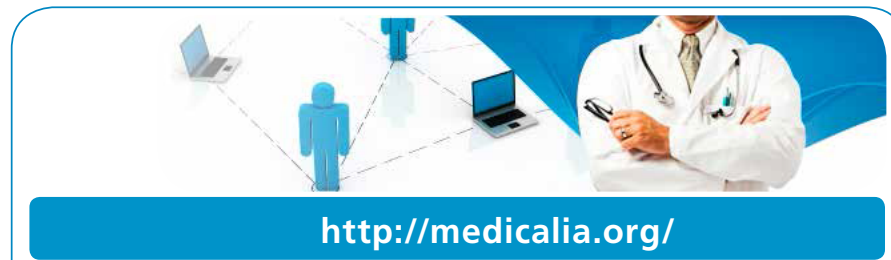

Where Doctors exchange clinical experiences, review their cases and share clinical knowledge. You can also access lots of medical publications for free. Join Now!

\section{Publish with iMedPub}

http://www.imed.pub

The Journal is an open access peer-reviewed journal that publishes scientific papers about all aspects of antimicrobials. The journal will publish original research articles, reviews, brief reports and case reports dealing with basic and clinical antibacterial agents, antiviral, antiprotozoals, antituberculuous, antifungal and antihelminthes agents.

All manuscripts must be prepared in English, and are subject to a rigorous and fair peer-review process. Accepted papers will immediately appear online.

The journal aims to advance the knowledge, attitude and the research of chemotherapy in the Arabic world in cooperation with international, national scientific and public societies as well as research centers with similar aims and objectives. 